\title{
Cutaneous Appendageal Neoplasms: A Histopathological Study from A Tertiary Care Centre in North Karnataka
}

\author{
Pritha M Guha and Prabhu M H*
}

Department of Pathology, S. N.Medical College, Bagalkot, Karnataka, India

\section{ABSTRACT}

Background: Skin appendages are sweat gland, sebaceous gland and hair follicle. Adnexal tumors arising from the skin are usually missed clinically and often confirmed by histopathology.Immunohistochemistry may further help in confirmation of the diagnosis.Tumors of cutaneous appendages are uncommon. The classification of these tumors is complex. They carry a wide histopathological spectrum. Hence, this study was undertaken to determine data about the neoplasms in this part of the country.Determination of the incidence, localization, age and sex distribution of cutaneous appendageal tumors was done.

Methods: This cross sectional study was done at a tertiary care centre in the Department of Pathology, S N Medical College, Bagalkot, Karnataka during the period of March 2010 to March 2015.Appendageal tumors of the skin diagnosed were included.Clinical history and findings were noted.Histopathological study was done usinghematoxylin and eosin stain and special stains wherever necessary.The data was analysed using SPSS version 20. Categorical data was expressed in terms of rates, ratios and percentages.

Results: A total 52 cases of cutaneous adnexal tumors were diagnosed on histopathological basis. There were 18 males (34.62\%) and 34 female cases $(65.38 \%)$. The most common sites affected were head and neck region 35 cases $(67.30 \%)$. The age ranged from 9 - 80 years, the most affected age groups were from 3rd and 6th decade. The spectrum included both benign and malignant tumors. The sweat gland tumorsformed the majority of tumors (25 cases). Tumors with follicular and sebaceous differentiation were also studied

Conclusion: Adnexal tumors of skin are uncommon and are mostly benign so surgical excision will suffice in most cases. These tumors are a wide and heterogenous group with overlapping and pleomorphic spectrum of morphology.Although majorities of adnexal tumors are benign, malignant counterparts are also rarely encountered.

\section{Keywords: Appendageal Neoplasms,Histopathology, Apocrine}

\section{Introduction}

Cutaneous appendageal neoplasms are a broad and heterogenous group of tumors which differentiate towards skin adnexal structures and are categorized further into eccrine,apocrine, follicular and sebaceous, based on histologic, ultrastructural and immunohistochemical analysis. These tumors due to their common origin are difficult to differentiate and diagnose. These neoplasms develop from pluripotent stem cells that are undifferentiated and present within the epidermis or the appendageal structures to finally differentiate into specific tumors which is influenced by genetics, local vascularity and the microenvironment of the epidermis and dermis. ${ }^{[1]}$

Most of the tumors in this group are benign. Malignant tumors are though uncommon and are not detected early, with poor outcome. Only few studies on cutaneous appendageal tumors are available in the literature, so the present study aims at analysing the pattern of appendageal neoplasms in our institution. The goal of this study is to determine the incidence, localization, age and sex distribution of cutaneous appendageal tumors and to study the histopathological attributes of tumors according to lineage of differentiation.

\section{Materials and Methods}

Appendageal tumors of the skin diagnosed in the Department of Pathology, S N Medical College, Bagalkot, Karnataka during the period of March 2010 to March 2015 were used as the data for this retrospective study. Clinical history and findings were noted. The histopathological specimens where fixed in $10 \%$ buffered formalin, processed and embedded in paraffin blocks. The tissue sections were taken and stained with routine hematoxylin and eosin stains. Special stains where used wherever necessary.

\section{Results}

In our study, total 52 cases of cutaneous adnexal tumors were diagnosed on histopathological basis. There were 18 males $(34.62 \%)$ and $34(65.38 \%)$ female cases. The male to female ratio was 1:1.9. The most common sites affected were head and neck region - 35 cases $(67.30 \%)$ followed by trunk - 8 cases $(15.42 \%)$. The other sites affected were the upper limbs, lower limbs and genital regions, constituting 
3 cases $(5.76 \%)$ each. Benign tumors comprised 43 cases $(82.69 \%)$ and malignant tumors of 9 cases $(17.31 \%)$. The age ranged from 9 - 80 years, the most affected age groups were from $3^{\text {rd }}$ and $6^{\text {th }}$ decade. According to differentiation, eccrine tumors constituted majority of 21 cases $(40.38 \%)$, followed by follicular tumors - 20 cases (38.46\%), sebaceous tumors - 7 cases $(13.47 \%)$ and apocrine tumors - 4 cases $(7.69 \%)$ as shown in Table-1.The sweat gland tumors (eccrine and apocrine differentiation) formed the majority of tumors ( 25 cases). Hidradenoma ( 6 cases) was the most common benign tumor of sweat gland (Figure 8) and 1 case each of Hidradenocarcinoma and Paget's disease of breast (Figure 3) were the malignant sweat gland tumors seen. Various other eccrine and apocrine tumors

Table 1 : Distribution according to differentiation.

\begin{tabular}{|c|c|c|}
\hline Direction of differentiation & Number of cases & Percentage \\
\hline Eccrine & 21 & $40.38 \%$ \\
\hline Follicular & 20 & $38.46 \%$ \\
\hline Sebaecous & 7 & $13.47 \%$ \\
\hline Apocrine & 4 & $7.69 \%$ \\
\hline Total & $\mathbf{5 2}$ & $\mathbf{1 0 0}$ \\
\hline
\end{tabular}

Table 2: Tumors of Eccrine And Apocrine Differentiation.

\begin{tabular}{|l|c|c|}
\hline $\begin{array}{l}\text { Sweat gland tumors } \\
\text { (Eccrine + Apocrine) }\end{array}$ & No of cases & Percentage \\
\hline Hidradenoma & 6 & $24.00 \%$ \\
\hline Cylindroma & 4 & $16 \%$ \\
\hline Hidradenoma papilliferum & 3 & $12 \%$ \\
\hline Hidrocystoma & 4 & $16 \%$ \\
\hline Mixed tumor with mucinous metaplasia & 1 & $4 \%$ \\
\hline Spiradenoma & 2 & $8 \%$ \\
\hline Syringocystadenoma papilliferum & 2 & $8 \%$ \\
\hline Tubular adenoma & 1 & $4 \%$ \\
\hline Hidradenocarcinoma & 1 & $4 \%$ \\
\hline Paget's disease of breast & 1 & $\mathbf{2}$ \\
\hline Total & $\mathbf{2 5}$ & $\mathbf{1 0 0 \%}$ \\
\hline
\end{tabular}

Table 3: Tumors of follicular differentiation.

\begin{tabular}{|l|c|c|}
\hline Pilar tumors & No of cases & Percentage \\
\hline Pilomatricoma & 15 & $75 \%$ \\
\hline Trichoblastoma & 2 & $10 \%$ \\
\hline Proliferating trichilemmal tumor & 3 & $15 \%$ \\
\hline Total & $\mathbf{2 0}$ & $\mathbf{1 0 0 \%}$ \\
\hline
\end{tabular}

Table 4: Tumors of sebaceous differentiation.

\begin{tabular}{|l|c|c|}
\hline Sebaceous gland tumors & No of cases & Percentage \\
\hline Sebaceoma & 3 & $42.85 \%$ \\
\hline Sebaceous carcinoma & 4 & $57.15 \%$ \\
\hline Total & 7 & $100 \%$ \\
\hline
\end{tabular}

Annals of Pathology and Laboratory Medicine, Vol. 5, Issue 4, April, 2018 encountered are listed in Table 2.Sysringocystadenoma papilleferum and Hidrocystoma have been depicted in the Figure 1 and Figure 4 respectively.Follicular tumors were seen in 20 cases and Pilomatricoma (15 cases) was the most common benign follicular tumor as shown in Table 3 and Figure 5. Proliferating trichilemmal tumor ( 3 cases) was the most common malignant tumor of follicular differentiation.Tumors with sebaceous differentiation the least common with 3 cases of benign sebaceoma (Figure 2) and 4 cases of sebaceous carcinoma ( Figure 7) as depicted in Table 4 . Pilomatricoma and Hidradenoma were the most common benign tumors of adnexal origin and most frequently encountered malignant tumor was sebaceous carcinoma. 


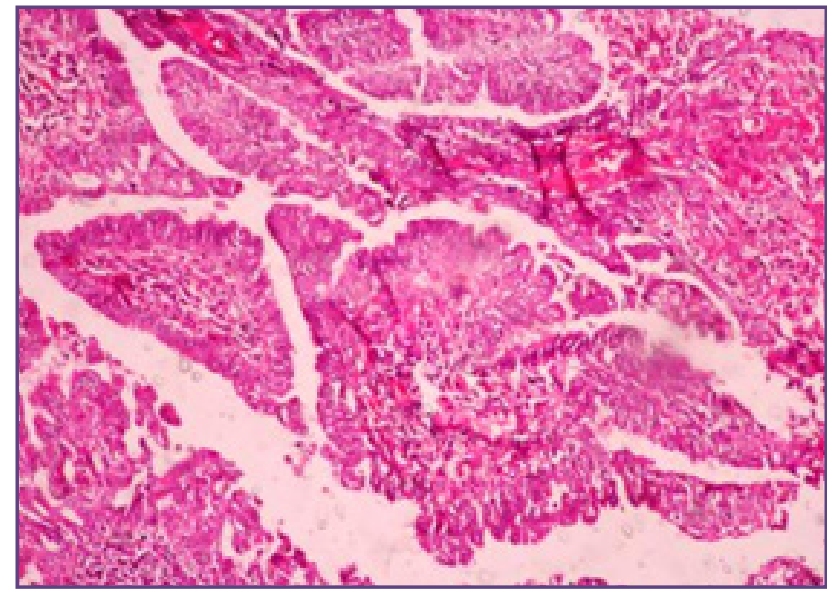

Fig. 1: Photomicrograph showing section of Syringocystadenoma papilliferum which shows papilliferous processes with double layer of epithelial cells. ( H\&E stain ; $100 \mathrm{X}$ ).

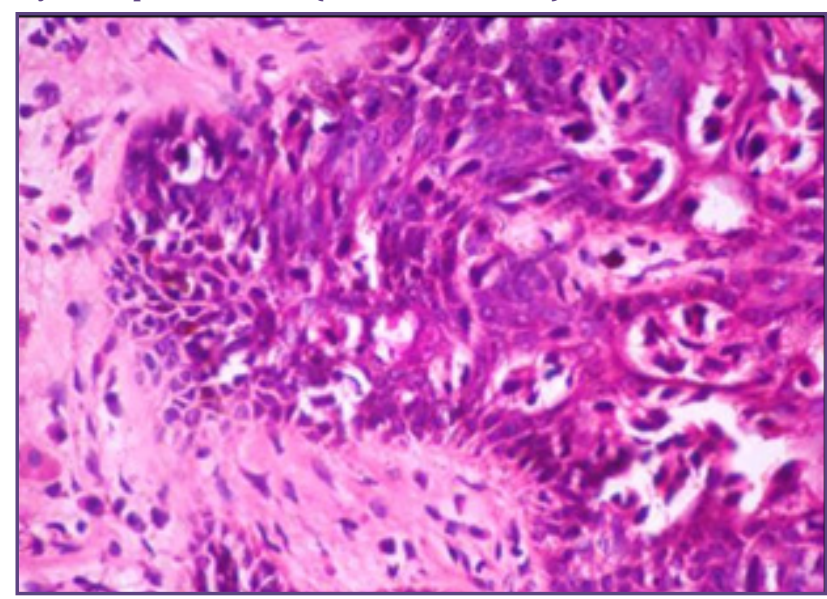

Fig. 3: Photomicrograph showing section of Pagets disease of breast showing atypical pagetoid cells in epidermis.( H\&E stain ; $100 \mathrm{X}$ ).

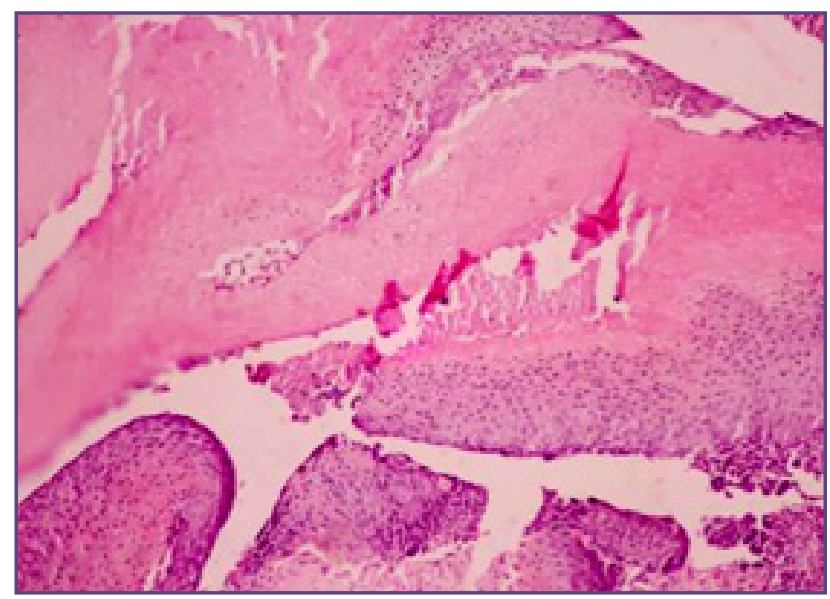

Fig. 5: Photomicrograph showing section ofPilomatricoma showing periphery of basophilic small cells with central ghost cells and keratin.( H\&E stain ; $100 \mathrm{X}$ ).

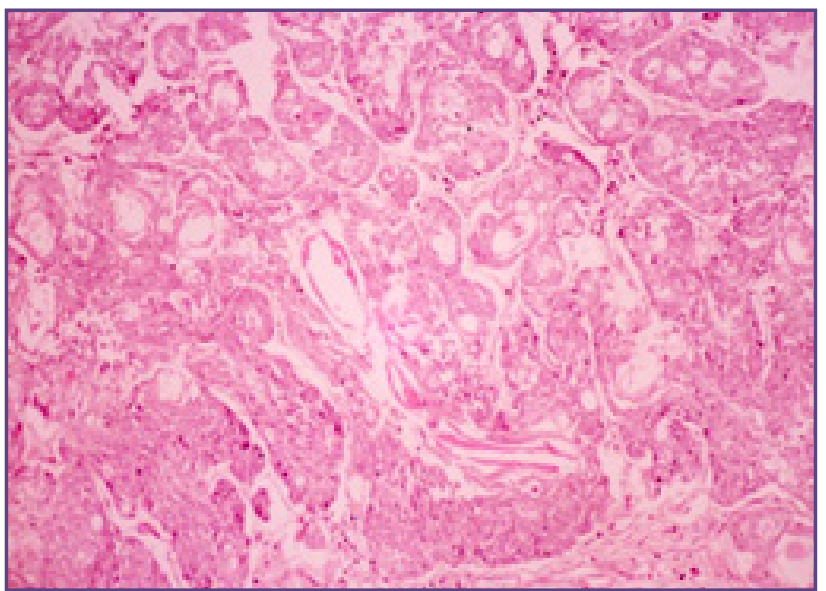

Fig. 2 : Photomicrograph showing section of Sebaceoma showing degenerated dark cells with light sebaceous cell. .( H\&E stain ; $100 \mathrm{X})$.

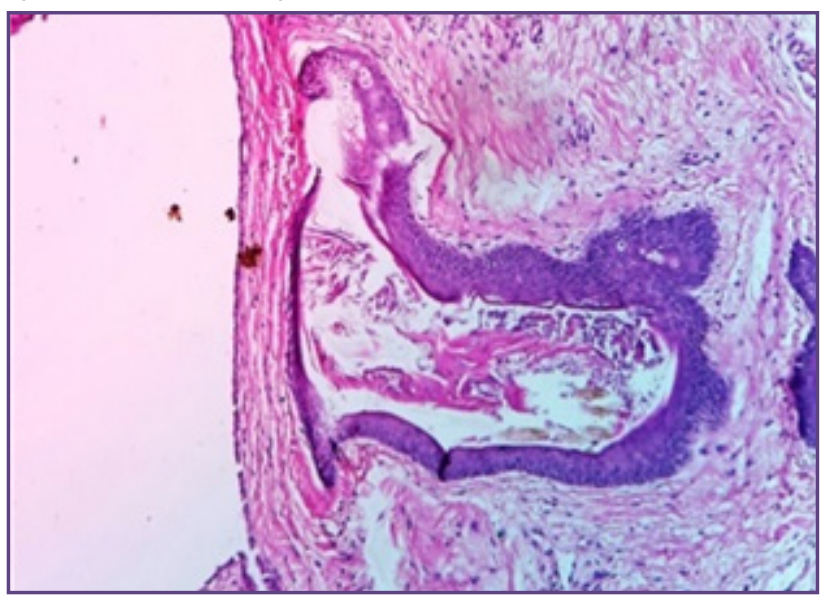

Fig. 4: Photomicrograph showing section ofHidrocystoma showing cyst lined by double layer of myoepithelial and epithelial layer.( H\&E stain ; $100 \mathrm{X}$ ).

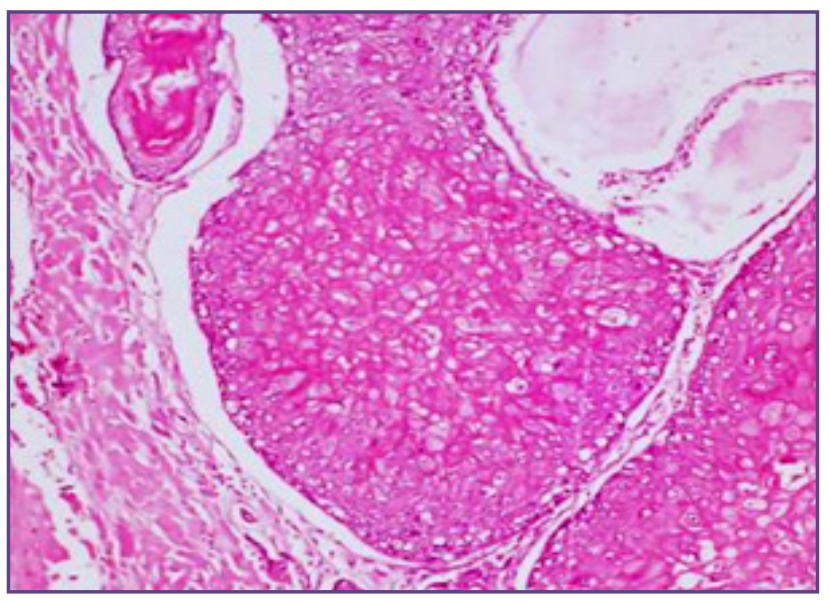

Fig. 6 : Photomicrograph showing section ofPilomatricoma showing proliferating trichilemmal tumor . Malignant cells are seen showing abrupt keratinization.(H\&E stain ;100 X) 


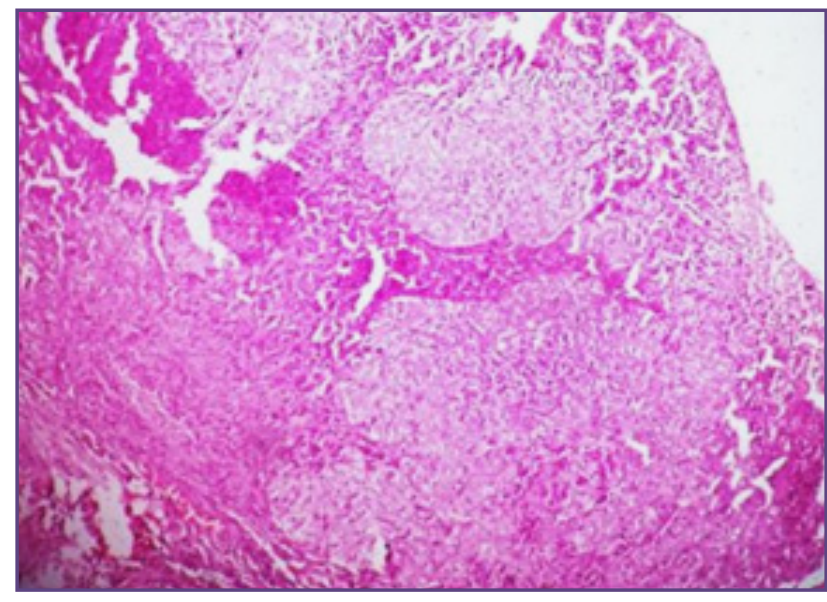

Fig. 7: Sebaceous carcinoma - Irregular lobules of atypical cells with sebaceous differentiation.( H\&E stain ; $100 \mathrm{X}$ ).

\section{Discussion}

Histopathological examination is required for establishing the diagnosis of appendageal neoplasms. Appendageal neoplasms mostly differentiate into more than one cell line in the same tumour as they originate from the pluripotent stem cells. ${ }^{[2]}$ Cutaneous adnexal tumors are uncommon, in our study period of 5 years only 52 cases were diagnosed. Most of the tumors were benign 43 cases $(82.69 \%)$ and malignant 9 cases $(17.31 \%)$, similar was noted in studies by Radhika et al. ${ }^{[3]}$ with $77.15 \%$ benign tumors and 22.85 $\%$ malignant tumors, Jindal et al ${ }^{[4]}$ showing $96 \%$ benign tumors and $4 \%$ malignant tumors. Tumors of the adnexa are differentiated according to lineage of adnexal differentiation, but in many cases the differentiation is unclear or mixed in origin. Even after immunohistochemical and electron microscopic analyses exact origin is not found. This may be due to pluripotent stem cell hypothesis, stating presence of stem cells which are able to differentiate along many lines. ${ }^{[5]}$ Malignancy in cutaneous appendageal tumors is not determined only by cytological and nuclear atypia. A list of criteria has been described by Ackerman to be applied to appendageal neoplasms which help differentiate benign from the malignant appendageal lesions ${ }^{[6]}$

So at present it is better to classify them according to their apparent histological differentiation. The following features favour Benign tumors : smooth borders, absence of ulceration of adnexa, vertical orientation with V-shape, uniform collection of epithelial cells with dense fibrotic stromal reactions around tumor cells and absence of mitosis, necrosis and atypia. ${ }^{[5]}$ Malignant tumors mostly have ulceration, necrosis, clefts between tumor cells and stroma. In our study the tumors were classified according to WHO histological classification of appendageal tumors

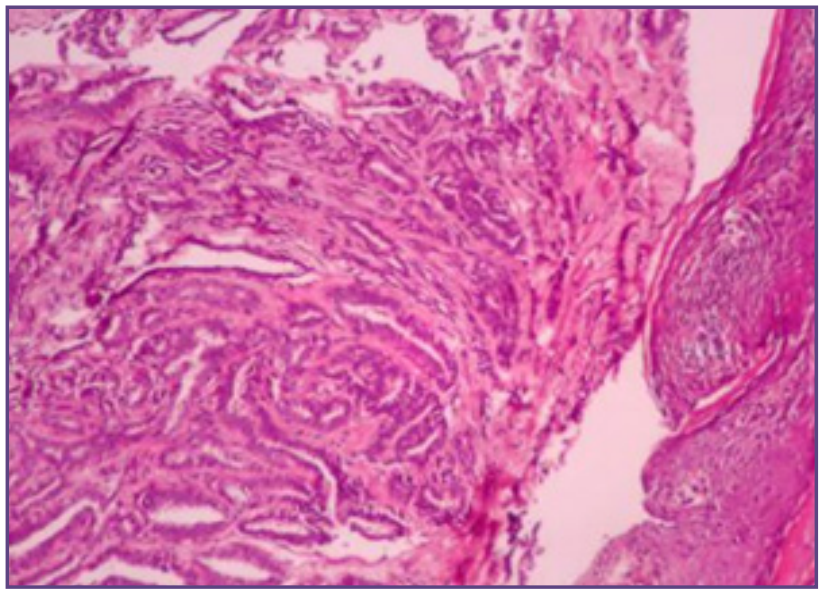

Fig. 8 : Photomicrograph showing section of Hidradenoma papilliferum which shows Papillary fronds lined by secretory cells.( H\&E stain ; $100 \mathrm{X}$ ).

${ }^{[7]}$ based on their apparent differentiation. The classification differentiates tumors into three categories, tumors of eccrine and apocrine differentiation, follicular differentiation and sebaceous differentiation. These tumors have overlapping features due to common origin and hence some neoplasms contain two or more appendageal elements in different degree of maturation. ${ }^{[8]}$ Clinical presentation of neoplasms is non-specific as many present with plaques, papules and nodules. ${ }^{[5]}$ Clinical presentation as asymptomatic papules or nodules over longer duration points more towards the benign neoplasms.Most of tumors were found to be of eccrine and apocrine differentiation (48.07\%) followed by follicular tumors $(38.46 \%)$ and sebaceous tumors (13.47\%) which was concordant with studies by Jindal et al. ${ }^{[2]}$, Ankit et al. ${ }^{[9]}$ and Nair et al. ${ }^{[1]}$ There was a female preponderance in our study (M:F ratio 1:1.9) and similar was noted in studies by Jindal et al ,Nair et al and Saha et al. ${ }^{[10]}$ Most of the tumors arose from the head and neck region $(67.30 \%)$ which was also noted by Jindal et al (64\%) and Ankit et al. (46\%). Nair et al. also found face (75.75\%) followed by scalp (12.12\%) as the most common sites affected. In our study the most common benign tumors were Pilomatricoma (29\%) and Hidradenoma (11\%). Sebaceous carcinoma was most common malignant tumor. In study done by Ankit et al. Clear cell Hidradenoma and Pilomatricoma were most common tumors. In a study done by Song et al. ${ }^{[1]}$ Pilomatricoma was the most common benign adnexal tumor.

\section{Conclusion}

Skin adnexal tumors are an uncommon entity. Most of the tumors are benign and only few malignant. These tumors are a wide and heterogenous group with overlapping 
and pleomorphic spectrum of morphology. Clinical presentation of appendageal neoplasms is often vague and non-specific. Histopathology is the gold standard for diagnosis of appendageal neoplasms. Diagnosis based on apparent histological differentiation is the better for microscopic study of tumors rather than detailed study for lineage, especially in benign tumors as the treatment of choice in them is simple excision. The adnexal tumors with sweat gland differentiation are the most common.

\section{Acknowledgement}

The authors would like to thank the patients for the support .We also thank the staff of Department of Pathology and Department of Dermatology, S Nijalingappa Medical College, Bagalkot Karnataka for their support.

\section{References}

1. Nair PS. A clinicopathologic study of skin appendageal tumors. Indian J Dermatol Venereol Leprol 2008;74:550-3.

2. Elder D,Elenitsas R, Ragsdale BD.Tumors of the epidermal appendages.In: Elder D, Elenitsas R, Jaworsky C, Johnson B Jr eds. Lever's Histopathology of the Skin. 8th Edition. Lippincott-Raven, Philadelphia-New-York,1997;747-803.

3. Radhika K, Phaneendra BV, Rukmangadha N, Reddy MK. A study of biopsy confirmed skin adnexal tumors: experience at a tertiary care teaching hospital.J Clin Sci Res. 2013;2:132-8.
4. Jindal U,Patel R. Study of Adnexal tumors of the skin: A three year study of 25 Cases. The Internet Journal of Pathology.2012;13(3):1-7.

5. Storm CA, Seykora JT. Cutaneous adnexal neoplasms.Am J Clin Pathol. 2002;118:33-49.

6. Ackerman AB. Differentiation of benign from malignant neoplasms by silhouette. Am J Dermatopathol.1989;11:297-300.

7. LeBoit P E , Burg G, Weedon D, Sarasin A. World Health Organization Classification of Tumors, Pathology and Genetics of Skin Tumors, Lyon, France: IARC Press International Agency for Research on Cancer. 2006:121-63.

8. Khandpur S, Ramam M. Skin Tumors. In: Valia RG, Valia AR, editors. I Dermatology 3rd ed. Mumbai: Balani Publishing House;2008.147.

9. Sharma A, Paricharak DG, Nigam JS, Rewri S, Soni BB, Omhare A et al. Histopathological Study of Skin Adnexal Tumors-Institutional Study in South India. J Skin Cancer.2014;543-56.

10. Saha A, Das NK, Gharami RC, et al. A clinicohistopathological study of Appendageal Skin Tumors, affecting head and neck region in patients Attending the Dermatology OPD of a tertiary care centre in Eastern India. Ind J Dermatol. 2011;56(1):33-6.

11. Song K Y, Yoon D H, Ham E K, Lee Y S. Clinicopathological study on the skin appendage tumors. Korean J Pathol.1989;23:111-21.

*Corresponding author:

Dr Prabhu M H, Associate Professor, Department of Pathology, S Nijalingappa Medical College, Bagalkot Karnataka (India)

Phone: +91 9243529531

Email: docprabhumh@gmail.com

Financial or other Competing Interests: None. 